https://dx.doi.org/10.4314/ijs.v20i2.22

Ife Journal of Science vol. 20, no. 2 (2018)

\title{
PHYSICOCHEMICAL PARAMETERS OF SOME PREPARED COSMETIC PRODUCTS AND THEIR COMMONLY USED COUNTERPARTS AVAILABLE IN NIGERIAN MARKETS: A COMPARATIVE ANALYSIS
}

\author{
Oyekunle, J. A. O., Olasode, A. O., Adekunle, A. S., Durodola, S. S.* and Ayinuola, O. \\ Department of Chemistry, Obafemi Awolowo University, Ile-Ife - 220005, Nigeria \\ *Corresponding author E-mail: solomonsun77@gmail.com; Phone number: +2347038171289
}

(Received: ; Accepted: )

\section{ABSTRACT}

\begin{abstract}
A comparative analysis of four laboratory formulated body care creams, namely: body cream, deodorant, balm and hair cream was carried out with respect to their commonly used counterparts, such as Venus Moisturising Cream, Pixy Stick Deodorant, Aboniki Balm and Apple Hair Cream. This was done with a view to determining the extent to which the laboratory formulated products conformed to the generally approved cosmetics standards. The Sun Protection Factor (SPF), specific gravity and levels of potentially toxic metals were carried out for the two categories of cosmetic products using standard methods. The SPF values of the commercially available products ranged between $5.95 \pm 0.25$ and $31.21 \pm 1.26$, while those of their laboratory formulated counterparts ranged from $1.51 \pm 0.06$ to $12.51 \pm 1.01$. The commercially procured cosmetics had a range of total metal loads of $129.70 \pm 2.29$ to $1047.75 \pm 8.62 \mu \mathrm{g} / \mathrm{g}$, while their formulated counterparts had a range of 136.16 \pm 2.40 to $762.85 \pm 6.41 \mu \mathrm{g} / \mathrm{g}$. The formulated hair cream had the highest SPF value and, hence, would protect scald skin far better than its commercially available counterparts. This study concluded that the laboratory formulated cosmetic products showed closely related properties with their commercially available counterparts.
\end{abstract}

Keywords: Cosmetics, Body cream, Balm, Hair cream, Physico-chemical parameters, Sun protection factor

\section{INTRODUCTION}

Cosmetics are make-up or body-care products used to enhance the appearance or odor of the human body. They are generally mixtures of chemical compounds derived from either natural (such as coconut oil) or synthetic sources (Gunther et al., 2005). Generally, cosmetics are preparations intended to be rubbed, poured, sprinkled, or sprayed on, introduced into, or otherwise applied to the human body or any part thereof for cleansing, beautifying, promoting attractiveness, or altering the appearance (Nishikawa et al., 2007). However, the term cosmetics do not include soap. Throughout the recorded history of man, cosmetics have been used with the goals of enhancing personal appeal through decoration of the body, camouflaging flaws in the integument, and altering or improving upon nature (Romm, 1992; Nishikawa et al., 2007).

Determination of physicochemical parameters of cosmetics is important with respect to preparation, storage and application of the products formulated (Isaac et al., 2008). Synthetic sunscreens are known to provide photoprotective actions, and hence, their incorporations in the formulations of cosmetic products meant for skin protection (Violante et al., 2009). Many of the cosmetics rubbed on the skin also serve as sunscreen agents that prevent the skin from sun burn (Vieira et al., 2009). The rapid growth of commercially available products containing sunscreen indicates that even though a suntan is still desired, people are conscious of the possible dangers of photo aging and skin cancer, occurring as a result of over exposure to the sun. According to Sax (2000), every year about one million people are diagnosed with skin cancer and about 10,000 die from the malignant melanoma most of which frequently occurred on the parts of the body regularly exposed to the sun, such as the face, neck, head and back of the hands.

The harmful effects of solar radiation are caused predominantly by the ultraviolet (UV) region of the electromagnetic spectrum, which can be divided into three regions: UVA (320 - $400 \mathrm{~nm})$; UVB (290 - $320 \mathrm{~nm})$; and UVC (200 - $290 \mathrm{~nm})$. Going by their intensity, UVC radiation is filtered by the atmosphere before reaching the earth, UVB radiation is not completely filtered out by the ozone layer and is responsible for the damage due to sunburn, while UVA radiation reaches the deeper layers of the epidermis and dermis and provokes the premature aging of the skin. Ultraviolet radiations have been implicated as a 
causative factor of skin cancer. Due to these facts, sunscreens substances are now incorporated into everyday products such as moisturizers, creams, lotions, shampoos, mousses, and other hair and skin preparations (Sax, 2000).

There are several cosmetic products in the market with various claims as to the effectiveness of the products in terms of their sunburn protective abilities and safety levels of toxic metals. The present study was designed to ascertain the various claims and compare the properties of the market products with those formulated in the laboratory.

\section{MATERIALS AND METHODS Sterilization of Apparatus}

The apparatus used, such as Mixer, Stirrer, Hot plate, Water bath, Thermometer, Weighing balance, Crucible, Measuring cylinder, volumetric flask, Pyrex beaker, watch glass, spatula, and aluminium cup were properly washed using a hot solution of liquid detergent and rinsed with tap water followed by distilled water and dried before use. The aluminium cup was further rinsed with acetone after which it was rinsed with distilled water.

\section{Study Design}

Classes of cosmetics prepared and compared included body cream, hair cream, balm and deodorant. Materials for these were purchased from various shops and outlets within Lagos metropolis. Various percentages were mixed together until a stable blend was obtained. Physicochemical properties for each of the prepared cosmetics were measured alongside those of commercial products for purpose of comparison. Each material plays a major role as summarized in Table 1.

Table 1: Primary Sources and Roles of Major Raw Materials used for the Study.

\begin{tabular}{|c|c|c|}
\hline Raw Materials & Sources & Roles \\
\hline 1. Paraffin Oil & $\begin{array}{l}\text { Non vegetable (mineral source), particularly a } \\
\text { distillate of petroleum }\end{array}$ & For medicinal purposes \\
\hline 2. Petroleum jelly & Petroleum & Skin protection \\
\hline 3. Lanolin & Wool & $\begin{array}{l}\text { Protect the skin from ravages of } \\
\text { the climate }\end{array}$ \\
\hline 4. Glycerin & Animals fats and oils & $\begin{array}{l}\text { Improves smoothness, provides } \\
\text { lubrication and moisturizes the } \\
\text { skin }\end{array}$ \\
\hline 5. Paraffin wax & Petroleum & $\begin{array}{l}\text { Added to soften and smoothen } \\
\text { skin }\end{array}$ \\
\hline 6. Glyceryl monostearate & $\begin{array}{l}\text { Esterification products of glycerin and stearic } \\
\text { acid }\end{array}$ & Acts as a preservative agent \\
\hline 7. Stearic acid & Saponification of fat and oil & Acts as a softening agent \\
\hline 8. Ethanol & Microbial fermentation of sugar & $\begin{array}{l}\text { Convey the active ingredients } \\
\text { designed to resist bacterial } \\
\text { growth on the body }\end{array}$ \\
\hline 9. Industrial camphor & Wood (Camphor tree) & $\begin{array}{l}\text { Acts as an antimicrobial and } \\
\text { anesthetic substance }\end{array}$ \\
\hline 10. Peppermint oil & Peppermint plant & $\begin{array}{l}\text { Reduces the chances of fungal } \\
\text { infection, provides relief from } \\
\text { pain, and gives a cooling } \\
\text { sensation to the skin. }\end{array}$ \\
\hline 11. Menthol & Corn Mint and Peppermint oil & $\begin{array}{l}\text { Performs counter irritation in } \\
\text { the body and serves as an } \\
\text { anesthetic. }\end{array}$ \\
\hline 12. Perfume & $\begin{array}{l}\text { Mixture of essential oils or aromatic } \\
\text { compounds, fixatives and solvent. }\end{array}$ & Gives the body pleasant scent. \\
\hline 13. Colour & Agricultural, biological or mineral substances. & $\begin{array}{l}\text { Enhances the appearance or } \\
\text { odour of the body. }\end{array}$ \\
\hline
\end{tabular}


Optimization of Raw Materials Combination for the Laboratory Production. Following a series of combination of the ingredients, the mixture that gave the optimal performance especially in terms of stability is listed in Table 2 below.

Table 2: List of Raw Materials Combination for the Laboratory Production

\begin{tabular}{|l|llll|}
\hline \multirow{2}{*}{ Materials } & \multicolumn{3}{|c|}{ Laboratory made cosmetic products } \\
\cline { 2 - 5 } & Hair Cream & Body Cream & Deodorant & Balm \\
\hline 1. Paraffin Oil & $192 \mathrm{~mL}$ & $30 \mathrm{~g}$ & - & $20 \mathrm{~mL}$ \\
2. Petroleum Jelly & $120 \mathrm{~mL}$ & $20 \mathrm{~g}$ & - & $120 \mathrm{~mL}$ \\
3. Lanolin & $24 \mathrm{~mL}$ & $15 \mathrm{~g}$ & - & - \\
4. Glycerin & $7 \mathrm{~g}$ & $4.5 \mathrm{~mL}$ & - & - \\
5. Paraffin Wax & $2 \mathrm{~g}$ & - & - & $1.5 \mathrm{~g}$ \\
6. Perfume & $\sim 1 \mathrm{~mL}$ & $1 \mathrm{~mL}$ & $7 \mathrm{~mL}$ & - \\
7. Colour & $0.2 \mathrm{~g}$ & $0.3 \mathrm{~g}$ & - & $-04 \mathrm{~g}$ \\
8. Glyceryl monostearate & - & $95 \mathrm{~g}$ & - & - \\
9. Distilled Water & - & $335 \mathrm{~g}$ & $30 \mathrm{~mL}$ & - \\
10. Stearic acid & - & - & $20 \mathrm{~g}$ & - \\
11. Ethanol & - & - & $112 \mathrm{~mL}$ & $1.5 \mathrm{~g}$ \\
12. Menthol & - & - & - & $1.5 \mathrm{~g}$ \\
13. Industrial Camphor & - & - & - & $15 \mathrm{Ml}$ \\
14 14. Peppermint Oil & - & - & - & \\
\hline
\end{tabular}

\section{Preparation Protocol for Laboratory Body} Care Products

\section{Hair Cream}

Accurately measured $192 \mathrm{~mL}$ of paraffin oil was put into an aluminum cup to which $2 \mathrm{~g}$ of paraffin wax and $0.2 \mathrm{~g}$ of color were added. The mixture was then placed in a water bath at a temperature of about $75^{\circ} \mathrm{C}$ and stirred continuously until the paraffin wax dissolved completely. Then, $120 \mathrm{~mL}$ of petroleum jelly was added and stirred properly until the petroleum jelly dissolved completely. When heating and stirring, $24 \mathrm{~mL}$ of lanolin was added followed by the addition of $7 \mathrm{~g}$ of glycerin. Perfume (about $1 \mathrm{~mL}$ ) was added after the wax had melted and the mixture temperature was about $35^{\circ} \mathrm{C}$. Vigorous mixing was done and the mixture was allowed to equilibrate at room temperature. After this, packaging was done.

\section{Body Cream}

Accurately weighed $15 \mathrm{~g}$ of lanolin, $20 \mathrm{~g}$ of petroleum jelly and $4.5 \mathrm{~mL}$ glycerin were added into $30 \mathrm{~g}$ of paraffin oil, after which $0.3 \mathrm{~g}$ of color and $95 \mathrm{~g}$ of glyceryl monostearate were added to the mixture, and then $335 \mathrm{~g}$ of distilled water was added. The mixture was then heated to about $85^{\circ} \mathrm{C}$ with continuous agitation, stirred until it cooled and finally, $1 \mathrm{~mL}$ perfume was added and the mixture was mixed properly and then packaged.

\section{Deodorant Produced in the Laboratory}

Accurately measured $30 \mathrm{~mL}$ of distilled water, 112 $\mathrm{mL}$ of ethanol, $20 \mathrm{~g}$ of stearic acid, were weighed into a round bottomed flask and then refluxed at $100^{\circ} \mathrm{C}$ for 1 hour until the stearic acid dissolved. The solution was then allowed to simmer for a few minutes before the addition of $7 \mathrm{~mL}$ of perfume was done. The mixture was then vigorously mixed and carefully packaged.

\section{Balm}

Twenty milliliters $(20 \mathrm{~mL})$ of paraffin oil was heated in an aluminum cup to a temperature of about $85^{\circ} \mathrm{C}$ was attained. Thereafter, $0.040 \mathrm{~g}$ of color, $120 \mathrm{~mL}$ of petroleum jelly, and $1.5 \mathrm{~g}$ of industrial camphor were added and stirred vigorously. Following this, $1.5 \mathrm{~g}$ of paraffin wax and $1.5 \mathrm{~g}$ of menthol were weighed, dissolved in the paraffin oil and mixed thoroughly. Finally, 15 $\mathrm{mL}$ of peppermint oil was added and the mixture was mixed properly in readiness for packaging.

\section{Determination of the physicochemical properties of the products Sunscreen protection factor (SPF)}

The method developed by Mansur et al. (1986) was adopted utilizing uv spectrometer is the following equation:

$S P F=C F \times \sum_{290}^{320} \operatorname{EE}(\lambda) \times I(\lambda) x A b s(\lambda)$ 
Where CF is correlation factor (10); $\mathrm{EE}(\lambda)$ is the erythemal effect spectrum; $I(\lambda)$ is solar intensity spectrum; $\operatorname{Abs}(\lambda)$ is absorbance of sunscreen product. The values, EE x I are constant determined by Sayre et al. (1979) and are contained in Table 3.

Table 3: Normalized product function used in the calculation of SPF

\begin{tabular}{|l|l|}
\hline \multicolumn{1}{|c|}{ Wavelength (nm) } & EE $\mathbf{x}$ I (Normalized) \\
\hline 290 & 0.0150 \\
295 & 0.0817 \\
300 & 0.2874 \\
305 & 0.3278 \\
310 & 0.1864 \\
315 & 0.0839 \\
320 & 0.0180 \\
\hline Total & 1.000 \\
\hline
\end{tabular}

Source: Sayre et al., 1979

To determine the SPF, accurately weighed $1.0 \mathrm{~g}$ of each sample was transferred into a $100 \mathrm{~mL}$ volumetric flask, diluted to volume with ethanol, followed by ultrasonication for 5 minutes and then filtered through cotton, rejecting the first $10 \mathrm{~mL}$. A $5.0 \mathrm{~mL}$ aliquot was transferred to $50 \mathrm{~mL}$ volumetric flask and diluted to volume with ethanol. Then a $5.0 \mathrm{~mL}$ aliquot was transferred to a $25 \mathrm{ml}$ volumetric flask and the volume completed with ethanol. The absorption data using UVVisible Spectrophotometer (Shimadzu UV-1800) were obtained in the range of 290 to $320 \mathrm{~nm}$, at 5 $\mathrm{nm}$ interval, taking ethanol as a blank. The measurements were taken thrice and the determinations were made at each point, followed by SPF determination using Mansur equation.

\section{Digestion of the Samples}

Accurately weighed $0.5 \mathrm{~g}$ of each sample was put into a Pyrex beaker, $10 \mathrm{~mL}$ of $\mathrm{HNO}_{3}$ was added and was placed on a thermostated hotplate in a fume cupboard and heated between $120-150^{\circ} \mathrm{C}$. The Pyrex beaker was covered with a watch glass while the content of the beaker was replenished with $\mathrm{HNO}_{3}$ from time to time to avoid total dryness. The mixture was then brought down to simmer for about 10 minutes before $2 \mathrm{~mL}$ of $\mathrm{HClO}_{4}$ was added and digested further until a clear solution was obtained. It was then allowed to cool. The content of the beaker was quantitatively transferred into a $25 \mathrm{~mL}$ volumetric flask and the volume was made to the mark with distilled water. For each digestion, a blank was also prepared.

\section{Determination of Specific Gravity}

A known amount of the cosmetic products was weighed into a beaker and placed on a hotplate and allowed to melt. It was transferred into a measuring cylinder and weighed. Distilled water was then measured at the same volume of the sample that was previously weighed and the specific gravity of the sample was estimated from:

$$
\text { Relative density of the sample }=\frac{(\mathrm{Y}-\mathrm{X}) \mathrm{g}}{(\mathrm{Z}-\mathrm{X}) \mathrm{g}}
$$

where $\mathrm{X}$ is weight of empty measuring cylinder; $\mathrm{Y}$ is weight of measuring cylinder with sample; $Z$ is mass of equal volume of distilled water + measuring cylinder; $\mathrm{Y}-\mathrm{X}$ is mass of the sample; and $\mathrm{Z}-\mathrm{X}$ is mass of distilled water.

\section{Quality Control Measures Adopted}

The quality control measures adopted were to ensure that results obtained met analytically reliable values. The measures included blank determination and spike recovery.

\section{Blank Determination}

Blank determination is an analysis of a sample without the analyte or sample, i.e. going through all steps of the procedure with the reagents only. The sample results were calculated by subtracting blank readings from sample readings.

\section{Recovery Analysis for Potentially Toxic Metals}

For recovery experiments, a given cosmetic 
sample was divided into two equal portions $\mathrm{A}$ and B. Portion A was spiked with a known quantity $C$ of the analyte of interest while portion $B$ was left unspiked. Both samples were carried through the digestion stages described earlier. Percentage recovery $(\% \mathrm{R})$ was calculated from the relationship:

$\% R=\frac{A-B}{C} \times 100$

\section{RESULTS AND DISCUSSION}

Evaluation of Analytical Procedures Used

The reliability of the analytical procedures used in this study was tested in terms of percentage recovery $(\% \mathrm{R})$. Table 4 shows the percentage recovery $(\% \mathrm{R})$ values of various analytes in cosmetic sample. Recovery values of trace metals in the sample ranged from $85.26 \% \mathrm{Zn}$ to $99.01 \%$ $\mathrm{Pb}$. Generally, \% $\mathrm{R}$ values obtained were within the $70-110 \%$ acceptable range for recovery as stipulated by the EU Guidelines for evaluating accuracy and precision of a method (European Union, 1999).

\section{Instrumental Calibration}

For FAAS, the standard calibration curves obtained showed high level of linearity with values of $\mathrm{r}^{2}$ ranging from 0.9892 for $\mathrm{Pb}$ to 0.9965 for $\mathrm{Cd}$ (Table 4). These values were considered reliable to give actual metal concentrations that are contained in the samples.

Table 4: Percentage Recovery $(\% \mathrm{R})$ of Analyte in Sample

\begin{tabular}{|lll|}
\hline Analyte & $\mathbf{0} \mathbf{R}$ & $\mathbf{r}^{\mathbf{2}}$ \\
\hline $\mathrm{Cd}$ & $96.39 \pm 4.25$ & 0.9965 \\
$\mathrm{Cr}$ & $98.25 \pm 2.39$ & 0.9912 \\
$\mathrm{Cu}$ & $97.75 \pm 3.11$ & 0.9932 \\
$\mathrm{Mn}$ & $98.15 \pm 2.06$ & 0.9945 \\
$\mathrm{~Pb}$ & $99.01 \pm 1.05$ & 0.9892 \\
$\mathrm{Zn}$ & $85.26 \pm 3.49$ & 0.9963 \\
\hline
\end{tabular}

\section{Sun Protection Factor of the Cosmetics Products}

The SPF values of both the produced and commercially available cosmetic products are listed in Table 5. Deodorants are applied to the body to prevent body odour caused by the bacterial breakdown of perspiration in armpits, feet, and other areas of the body. The commercial and produced deodorants had SPF values of 5.95 \pm 2.25 and $5.41 \pm 0.31$, respectively. According to the FDA regulations, both can help prevent sunburn only and not prevent skin cancer and premature aging of the skin since their SPF values are less than the values (15) recommended by the FDA.

Body cream is used to prevent dry, cracked skin and keep it supple and moisturized. The SPF values of commercial and produced body cream were $7.06 \pm 0.33$ and $5.73 \pm 0.29$, respectively. By implication and according to FDA regulations, both would protect the skin from sunburn only, although the commercial body cream will protect the skin from sunburn more than the produced body cream due to its higher SPF value.

Hair cream is used to make hair stronger and healthier and also prevents the sun from damaging the hair; the hair cream is also absorbed by the skin of the scalp when applied to the hair. The commercial and produced hair creams had SPF values of $1.51 \pm 0.06$ and $31.21 \pm 1.26$, respectively. The produced hair cream will not only protect against sunburn, but can also reduce the risk of skin cancer and early skin aging because of its higher SPF value. Conversely its commercial counterpart, with very low SPF value, would not even protect the skin adequately since its SPF value was not even in the range $2-14$ as recommended by FDA to just protect the skin from sunburn.

Balm is a fragrant or mentholated cream or liquid used to heal or soothe the skin with the SPF values of the commercial and produced balms of 20.82 \pm 1.06 and $12.51 \pm 1.01$ respectively, it is obvious that the commercial balm would protect the skin better than the produced balm due to its higher 
SPF value.

The effectiveness of the cosmetic products in decreasing order of protecting the skin from sunburn, skin cancer and early skin aging is as follows: produced hair cream $>$ commercial balm $>$ produced balm $>$ commercial body cream $>$ commercial deodorant $>$ produced body cream $>$ produced deodorant $>$ commercial hair cream.

\section{Table 5: Sun Protection Factor (SPF) Values of the Commercial and Laboratory Produced Cosmetic Products}

\begin{tabular}{|ll|}
\hline Cosmetic Products & SPF Value \\
\hline Commercial Deodorant & $5.95 \pm 2.25$ \\
Produced Deodorant & $5.41 \pm 0.31$ \\
Commercial Hair Cream & $1.51 \pm 0.06$ \\
Produced Hair Cream & $31.21 \pm 1.26$ \\
Commercial Body Cream & $7.06 \pm 0.33$ \\
Produced Body Cream & $5.73 \pm 0.29$ \\
Commercial Balm & $20.82 \pm 1.06$ \\
Produced Balm & $12.51 \pm 1.01$ \\
\hline
\end{tabular}

FDA recommended values: $\geq 15$

Result $=$ mean of triplicate determinations \pm standard deviation.

\section{Levels of Potentially Toxic Metals in the Products}

The levels $(\mu \mathrm{g} / \mathrm{g})$ of potentially toxic metals $(\mathrm{Cd}$, $\mathrm{Cr}, \mathrm{Cu}, \mathrm{Mn}, \mathrm{Pb}$ and $\mathrm{Zn}$ ) in both the produced and commercially available cosmetic products are listed in Table 6. The commercial deodorant and body cream showed higher levels of cadmium with values $12.50 \pm 1.03$ and $2.75 \pm 0.07 \mu \mathrm{g} / \mathrm{g}$, respectively, in comparison with its produced counterparts with values $4.65 \pm 0.02$ and $1.70 \pm$ $0.12 \mu \mathrm{g} / \mathrm{g}$, respectively. The levels of cadmium in the commercial balm and hair cream were lower with values $4.45 \pm 0.15$ and $3.90 \pm 0.04 \mu \mathrm{g} / \mathrm{g}$ respectively as compared to their laboratory produced counterparts which gave values of 9.05 \pm 0.15 and $7.80 \pm 1.01 \mu \mathrm{g} / \mathrm{g}$, respectively. Absorption of cadmium through the skin is low $(0.5 \%)$ and would be of concern only in situations where concentrated solutions would be in contact with the skin for several hours or longer but according to Food and Drug Agency (FDA), the recommended limit for the absorption of cadmium in the skin is $0.0005 \mu \mathrm{g} / \mathrm{g}$ (Food and Drugs Act, 2012). The highest cadmium level in the cosmetic products is $12.50 \pm 1.03 \mu \mathrm{g} / \mathrm{g}$; it implies that the products are not really safe for continuous and regular use because it is far greater than the recommended value by FDA. The products are not, however, expected to stay for a long period of time on the skin before bathing take place. All the same, continuous regular skin applications of the product could manifest in cadmium induced skin problems.

The commercial deodorant and hair cream had lower lead levels with values $4.29 \pm 0.03$ and 19.45 $\pm 0.98 \mu \mathrm{g} / \mathrm{g}$ respectively as compared to their produced counterparts with values $5.30 \pm 0.05$ and $24.05 \pm 1.04 \mu \mathrm{g} / \mathrm{g}$ respectively. Commercial body cream and balm had higher lead levels with values $11.20 \pm 0.84$ and $34.85 \pm 1.03 \mu \mathrm{g} / \mathrm{g}$ respectively than their produced counterparts whose values were $7.35 \pm 0.25$ and $28.00 \pm 1.59$ $\mu \mathrm{g} / \mathrm{g}$ respectively. The limit for lead impurities of cosmetic products applied to the skin as regulated by FDA is $10 \mu \mathrm{g} / \mathrm{g}$. The effect of lead in the body by absorption is very quick and consequently is very harmful. Therefore, the skin should not be exposed to lead let alone at a high proportion. In fact, lead has been described as the most severe environmental contaminant to arise in human civilization (Chukwuma, 1997). Lead absorbed through the skin may be eliminated via sweat and other extracellular fluids and hence might not be as great a health hazard as ingested lead (Lilley et al., 1988). However, using minimal amounts of 
deodorant at a time is highly recommended to limit dermal exposure through deodorant application.

Other metals, such as Copper, Manganese, Zinc and Chromium, may be present as impurities in cosmetic products. However, the toxicological properties and corresponding risk associated with these substances are considered less significant than for lead, arsenic, cadmium, mercury and antimony, A limit of $100 \mu \mathrm{g} / \mathrm{g}$ has been set for cosmetic products by FDA (FDA, 2003). Accordingly, precise impurity limits in cosmetics have not been developed for these metals. In the present study, the highest levels of Chromium, Manganese, Zinc and Copper in the cosmetic products were $30.85 \pm 1.28,950.25 \pm 8.31,304.90$ \pm 5.51 and $5.85 \pm 0.61 \mu \mathrm{g} / \mathrm{g}$, respectively. These values were below the (FDA, 2003) recommended value. It implies that from the point of view of levels of $\mathrm{Cr}, \mathrm{Mn}, \mathrm{Zn}$ and $\mathrm{Cu}$ in the cosmetic products, no skin problem is envisaged.

Table 6: Levels $(\mu \mathrm{g} / \mathrm{g})$ of Potentially Toxic metals in the Products

\begin{tabular}{|l|lllllll|}
\hline \multirow{2}{*}{$\begin{array}{l}\text { Sample } \\
\text { Code }\end{array}$} & \multicolumn{7}{|c|}{ Concentration of metals $(\mu \mathrm{g} / \mathrm{g})$ in Products } \\
\cline { 2 - 8 } & $\mathrm{Cd}$ & $\mathrm{Cr}$ & $\mathrm{Cu}$ & $\mathrm{Mn}$ & $\mathrm{Pb}$ & $\mathrm{Zn}$ & $\begin{array}{c}\text { Total metal } \\
\text { load }\end{array}$ \\
\hline CDT & 12.50 & 3.60 & 1.95 & 118.60 & 4.29 & 304.90 & 445.84 \\
& \pm 1.03 & \pm 1.11 & \pm 0.27 & \pm 3.21 & \pm 0.03 & \pm 5.51 & \pm 6.56 \\
PDT & 4.65 & 4.05 & 5.80 & 129.50 & 5.30 & 112.20 & 261.50 \\
& \pm 0.02 & \pm 0.11 & \pm 0.17 & \pm 4.57 & \pm 0.05 & \pm 3.00 & \pm 5.47 \\
$\mathrm{CHC}$ & 3.90 & 4.65 & 4.70 & 31.35 & 19.45 & 108.10 & 172.15 \\
& \pm 0.04 & \pm 0.21 & \pm 0.71 & \pm 1.00 & \pm 0.98 & \pm 4.52 & \pm 4.79 \\
PHC & 7.80 & 7.95 & 5.85 & 58.36 & 24.05 & 32.15 & 136.16 \\
& \pm 1.01 & \pm 0.33 & \pm 0.61 & \pm 1.30 & \pm 1.04 & \pm 1.22 & \pm 2.40 \\
$\mathrm{CBC}$ & 2.75 & 8.05 & 1.25 & 950.25 & 11.20 & 74.25 & 1047.75 \\
& \pm 0.07 & \pm 1.77 & \pm 0.04 & \pm 8.31 & \pm 0.84 & \pm 1.15 & \pm 8.62 \\
PBC & 1.70 & 30.85 & 4.55 & 627.65 & 7.35 & 90.75 & 762.85 \\
& \pm 0.12 & \pm 1.28 & \pm 0.33 & \pm 6.01 & \pm 0.25 & \pm 1.79 & \pm 6.41 \\
CB & 4.45 & 12.50 & 0.90 & 41.45 & 34.85 & 35.55 & 129.70 \\
& \pm 0.15 & \pm 1.37 & \pm 0.02 & \pm 1.19 & \pm 1.03 & \pm 0.89 & \pm 2.29 \\
PB & 9.05 & 19.85 & 1.55 & 50.15 & 28.00 & 28.40 & 137.00 \\
& \pm 0.15 & \pm 1.37 & \pm 0.08 & \pm 1.33 & \pm 1.59 & \pm 1.29 & \pm 2.80 \\
Range & $1.70-12.50$ & $3.60-30.85$ & $0.90-5.85$ & $31.35-950.25$ & $4.29-34.85$ & $28.40-304.90$ & \\
\hline
\end{tabular}

Result $=$ mean of triplicate determinations \pm s.d.

CBC - Commercial Body Cream; PBC- Produced Body Cream

CDT - Commercial Deodorant; PDT- Produced Deodorant

CHC - Commercial Hair Cream; PHC- Produced Hair Cream

CB - Commercial Balm; PB- Produced Balm

Specific Gravity Values of Commercial and Produced Cosmetic Products

The specific gravity (s.g.) values of the commercial and produced cosmetic products are listed in Table 7. The s.g. values indicated that both the commercial and produced cosmetic products are closely related in terms of density related properties. Besides, virtually all the products can readily be washed off body surfaces with the aid of soaps, since their s.g. were generally lower than that of water (which is 1), except for commercial body cream and produced balm whose specific gravity were slightly higher than that of water.

The commercial body cream and produced balm that had specific gravities higher than 1 would stay longer on the skin than the others whose specific gravities were less than 1 . This implies that commercial body cream and produced balm would penetrate into the skin deeper and hence protect the skin better from UV radiation, premature skin aging and risk of cancer than the others. 
Table 7: Specific Gravity Values of the Products

\begin{tabular}{|ll|}
\hline Samples & Specific Gravity Values \\
\hline Commercial Body Cream & $1.01 \pm 0.35$ \\
Produced Body Cream & $0.99 \pm 0.12$ \\
Commercial Deodorant & $0.81 \pm 0.15$ \\
Produced Deodorant & $0.89 \pm 0.11$ \\
Commercial Hair Cream & $0.76 \pm 0.05$ \\
Produced Hair Cream & $0.83 \pm 0.03$ \\
Commercial Balm & $0.94 \pm 0.06$ \\
Produced Balm & $1.07 \pm 0.13$ \\
\hline
\end{tabular}

Result $=$ mean of triplicate determinations \pm standard deviations.

\section{CONCLUSION}

From the results of this study, the physicochemical parameters of the cosmetic products prepared in the laboratory compared favourably with their commercially available counterparts. Three of the laboratory produced cosmetic products had higher SPF values, and hence, would protect the skin from UVB rays than the commercially available ones. Regular use of the commercial products might result in continuous exposure of the skin to UVB rays than expected when the cosmetic products are applied to the skin and hair as a result of their low SPF values. In addition, commercially available cosmetic products contained higher percentage of heavy metals, and hence, could pose some skin and health challenges as a result of the accumulation of potentially toxic metals in the body through the skin. It is recommended that commercially available cosmetics be subjected to routine checks of their physicochemical parameters to ensure their safety.

\section{REFERENCES.}

Chukwuma, C. S. 1997. Environmental Lead Exposure in Africa, Ambio. 26 (6): 399-403.

European Union, EU. 1999. European Union Directive 1999/74/EC. Laying down minimum standard for protection.

Food and Drugs Act, Canada. 2012. Guidance on Heavy Metal Impurities in Cosmetics.

Food and Drug Administration. 2003. Guidance on heavy metal impurities in cosmetics, Reports and Publications for industry and health.

Gunther, S., Sven, G., Jorg, S., Waltraud, K., Uwe, S., Harmut, S. L., Annegret, K., Xenia, P., Wolfgang, P., Hellmut, I., and Walter, D. 2005. Skin Cosmetics, Ullmann's Encyclope diaofindustria chemistry, 24:219-230.
Isaac, V.L.B, Cefali, L.C., Chiari, B.G., Oliveira, C.C.L.G., Salgado, H.R.N. and Corrêa, M.A. 2008. Protocolo para enasaios fisicoquímicos de estabilidade de fitocosméticos, Rev. Ciénc. Farm. Básica Apl. 29: 81-96.

Lilley, S. G., Florence, T. M., Stauber, J. L. 1988. The use of sweat to monitor lead absorption through the skin, Science of the Total Environment, 76: 267-278.

Mansur, J.S., Breder, M.N.R., Mansur, M.C.A. and Azulay, R.D. 1986. Determinação do fator de proteção solar por espectrofotometria. An. Bras. Dermatol., 61:121-124.

Nishikawa, D.O., Zague, V., Pinto, C.A.S.O., Vieira, R.P., Kaneko, T.M., Velasco, M.V.R. and Baby, A.R. 2007. Avaliação da estabilidade de máscaras faciais peel-off contendo rutina. Rev. Cienc. Farm. Básica Apl., 28(2): 227-232.

Romm, S. 1992. The Changing Face of Beauty. St. Lonis:Mosby-Yearbook, Inc.

Sax, B.W. 2000. Educating Consumers about sun protection, Pharm. Times, New York, 66(5): 48-50.

Sayre, R. M., Agin, P. P., Levee, G. J., and Marlowe, E. 1979. Comparison of in vivo and in vitro testing of sunscreening formulas. Photochem. Photobiol., Oxford, 29: 559-566.

Vieira, R.P., Fernandes, A.R., Kaneko, T.M., Consiglieri, V.O., Pinto, C.A.S., Pereira, C.S.C., Baby, A.R. and Velasco, M.V.R. 2009. Physical and physicochemical stability evaluation of cosmetic formulations containing soybean extract fermented by Bifidobacterium animalis, Brazilian Journal of Pharmaceutical Sciences, 45 (3): 515-525.

Violante, I.M.P., Souza, I.M., Venturini, C.L., Ramalho, A.F.S., Santos, R.A.N., Ferrari, M. 2009. Avaliação in vitro da atividade fotoprotetora de extratos vegatais do cerrado de Mato Grosso. Braz: J. Pharmacog., 19: $452-457$. 